\title{
Effects of Biomass and Soil Water Content Distribution on Cosmic-ray Neutron Probes Measurement
}

\author{
Qiuming Wang ${ }^{1}$, Jun Fan², Xu Zhao ${ }^{2}$, and Scott B. Jones ${ }^{3}$ \\ ${ }^{1}$ Peking University \\ ${ }^{2}$ Northwest A\&F University \\ ${ }^{3}$ Utah State University
}

January 19, 2022

\begin{abstract}
The cosmic-ray neutron probe (CRNP) provides continuous monitoring of average near-surface soil water content (SWC) on a hectometer scale. However, the performance of the CRNP in surfaces of highly heterogeneous vegetation and SWC caused by the highly eroded terrain remains uncertain. This study evaluated three different vegetation calibration methods developed for CRNP on the Loess Plateau, compensating for the privious lack of vegetation correction for CRNP in this area. The landscape biomass and its distribution within the CRNP footprint of a small watershed on the Chinese Loess Plateau were measured using an unmanned aerial vehicle (UAV) equipped with a visible light camera and a Rededge multispectral camera. Three CRNPs were installed at three different locations including loamy sand hills (LSH) plot, silty loam dam (SLD) plot, and a sandy loam slope (SLS) plot and electronic sensors of SWC were buried at various depths in each of the three plots. We found the parameter, N0, was best represented by the biomass at the average growth conditions of the monitoring period, yielding the lowest RMSE (0.068). The variation of spatio-temporal distribution of SWC reduced the representativeness of the CRNP to the regional average SWC. The CRNP SWC calibrated using the three methods at three sites yielded similar temporal changes with precipitation. The three methods each reduced the RMSE between the estimated CRNP SWC and the kriging weighted SWC with the BWE (biomass water equivalent) corrected method, Veg-N0 method having the lowest RMSE. The correction of the spatial distribution of vegetation using the three methods further reduced the RMSE, in the order: $\mathrm{LSH}<\mathrm{SLS}<\mathrm{SLD}$. The cooperation between CRNP and UAV could obtain regional averaged SWC accurately, which should be useful for formulation sustainable vegetation management strategies on the Loess Plateau and regions with water scarcity possibly around the world.
\end{abstract}

\section{Hosted file}

Manuscript.docx available at https://authorea.com/users/456190/articles/553328-effects-ofbiomass-and-soil-water-content-distribution-on-cosmic-ray-neutron-probes-measurement













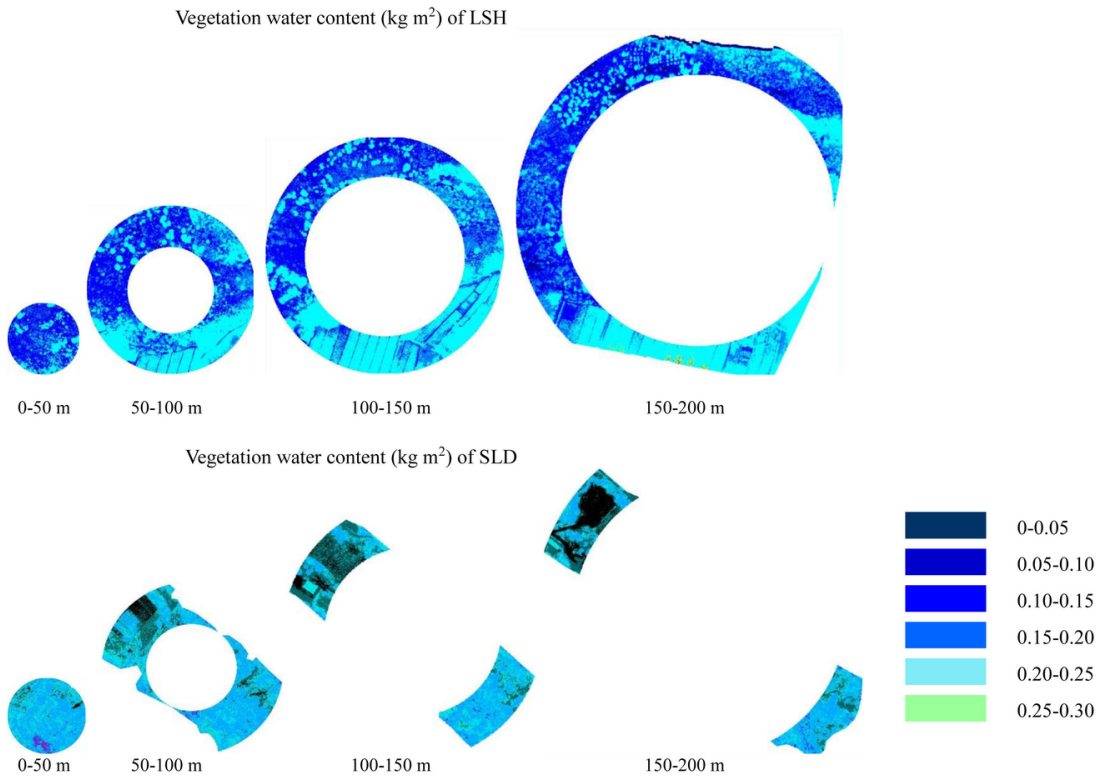

Vegetation water content $\left(\mathrm{kg} \mathrm{m}^{2}\right)$ of SLS

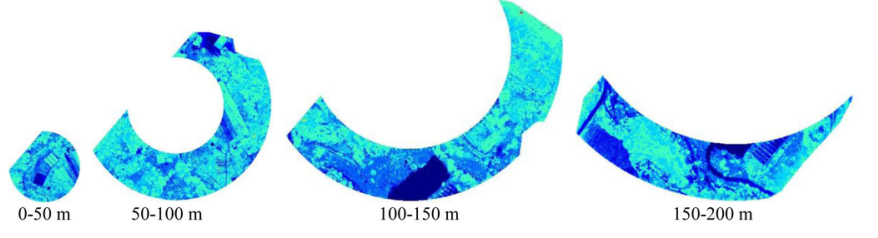



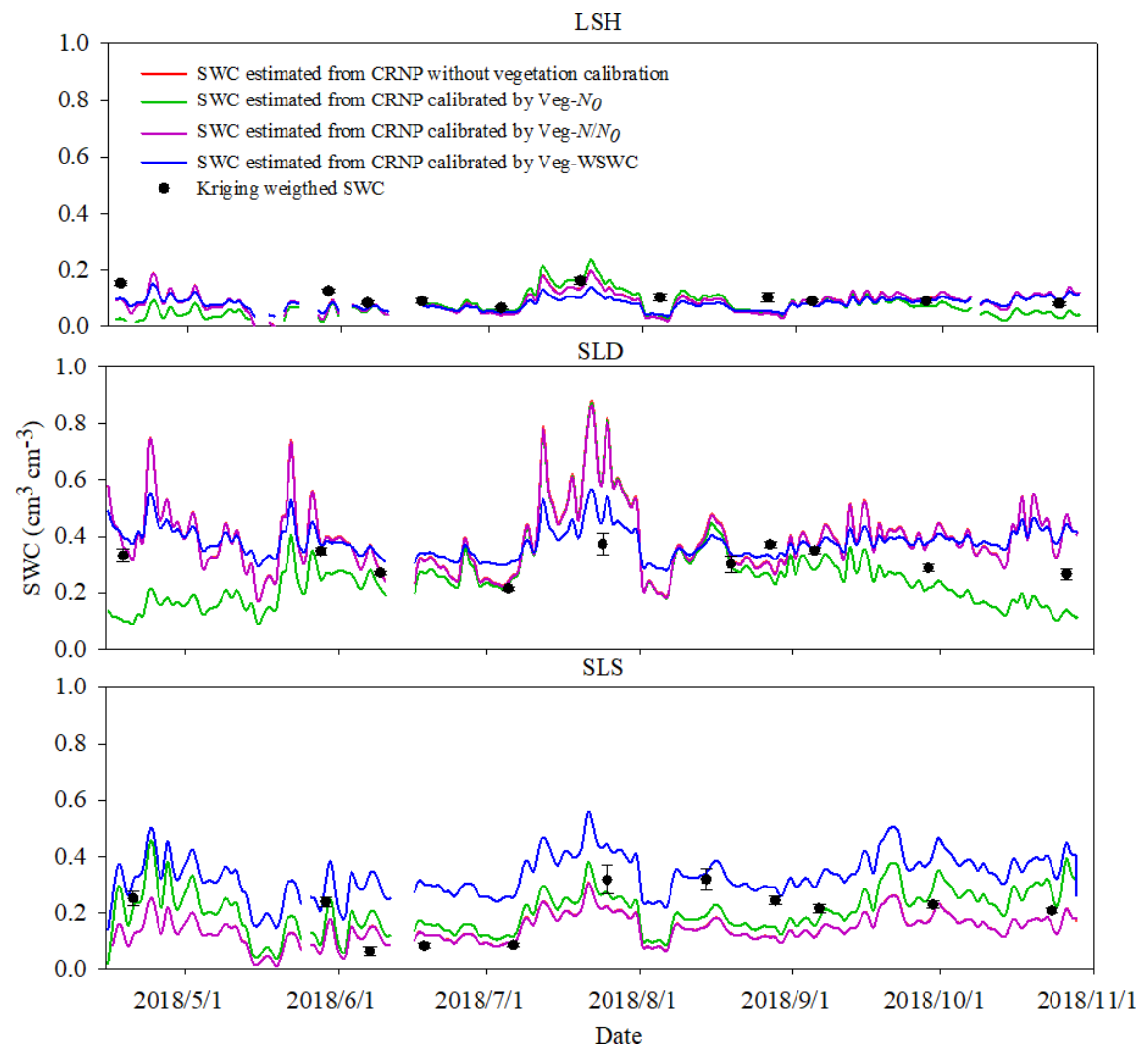